\title{
EFFECTS OF A GROUP PSYCHOEDUCATION PROGRAM ON SELF-STIGMA, EMPOWERMENT AND PERCEIVED DISCRIMINATION OF PERSONS WITH SCHIZOPHRENIA
}

\author{
Slađana Štrkalj Ivezić ${ }^{1}$, Marijan Alfonso Sesar ${ }^{2} \&$ Lana Mužinić ${ }^{3}$ \\ ${ }^{1}$ Psychiatric Clinic Vrapče, Zagreb, Croatia \\ ${ }^{2}$ Rehabilitation Center Silver, Zagreb, Croatia \\ ${ }^{3}$ Department of Psychiatry, University Hospital Dubrava, Zagreb, Croatia
}

received: 1.9.2016;

revised: 7.12.2016;

accepted: 9.1.2017

\section{SUMMARY}

Background: Self-stigma adversely affects recovery from schizophrenia. Analyses of self stigma reduction programs discovered that few studies have investigated the impact of education about the illness on self-stigma reduction. The objective of this study was to determine whether psychoeducation based on the principles of recovery and empowerment using therapeutic group factors assists in reduction of self-stigma, increased empowerment and reduced perception of discrimination in patients with schizophrenia.

Subjects and methods: 40 patients participated in psychoeducation group program and were compared with a control group of 40 patients placed on the waiting list for the same program. A Solomon four group design was used to control the influence of the pretest. Rating scales were used to measure internalized stigma, empowerment and perception of discrimination. Two-way analysis of variance was used to determine the main effects and interaction between the treatment and pretest. Simple analysis of variance with repeated measures was used to additionally test effect of treatment onself-stigma, empowerment and perceived discrimination.

Results: The participants in the psychoeducation group had lower scores on internalized stigma $(F(1,76)=8.18 ; p<0.01)$ than the patients treated as usual. Analysis also confirmed the same effect with comparing experimental group before and after psychoeducation $(F(1,19)=5.52 ; p<0.05)$. All participants showed a positive trend for empowerment. Psychoeducation did not influence perception of discrimination.

Conclusion: Group psychoeducation decreased the level of self stigma. This intervention can assist in recovery from schizophrenia.

Key words: self-stigma - schizophrenia - psychosis - empowerment - perceived discrimination - anti-stigma program

$$
* * * * *
$$

\section{INTRODUCTION}

Self-stigma or internalized stigma refers to the process of identity transformation related to accepting stereotyped attitudes towards mental illness by a person with mental illness as personally relevant, which leads to decrease in self-esteem and self-efficacy (Link et al. 2001, Corrigan et al. 2006), difficulties in recovery and leads to a variety of negative consequence in a vicious cycle of stigma (Sartorius et al. 2005). Research suggests that almost half of the patients with schizophrenia have moderate to high level of self-stigma and more than half perceive discrimination (Brohan et al. 2010). Studies also suggest an association between high levels of internalized stigma and reduced perception of empowerment as well as increased perception of discrimination (Brohan et al. 2010). Perceived discrimination is the extent to which a person believes that most people will devalue or discriminate against someone with a mental illness (Link 1987). Empowerment is the link between feelings of competence, self esteem, self - efficacy and the desire and intention to take action in the social sphere and to control ones own life (Rappaport 1987, Rogers et al. 1997, Liberman 2008).
A literature review of self-stigma reduction programs for patients with schizophrenia revealed a small number of successful programs, which used psychoeducation alone (Shin \& Lukens 2002, Aho-Mustonen et al. 2011) or psychoeducation combined with another method such as cognitive therapy (Knight et al. 2006, McCay et al. 2006, MacInnes and Lewis 2008, Fung et al. 2011, Lucksted et al. 2011). These studies differed in their concept of self-stigma, often had no clear theoretical framework and use different instruments to measure stigma (Mittal et al. 2012). Two pure psychoeducation programs were successful in reducing self-stigma (Shin \& Lukens 2002, Aho-Mustonen et al. 2011). The first (Aho-Mustonen et al. 2011) tested an education group program for patients with schizophrenia based on the stress-vulnerability model. The results showed increases in self-esteem, but not in decrease the perception of stigma. The second (Shin \& Lukens 2002) used a manual based culturally sensitive education program in a group setting. The results showed decreased perception of stigma as measured by The Perceived Devaluation and Discrimination Scale (PDD) (Link et al. 1989). Other programs used a combination of different inputs of education about the illness and the most common cognitive approaches in a 
group setting. McCayet al. (2006) provided a groupbased intervention for young adults with first episode psychosis focusing on teaching skills to reduce "engulfment," a process of acceptance of the role of the patient as the primary definition of self. They found a significant improvement in self-concept, increase in confidence and self-efficacy, reduced engulfment, self-stigma and increased quality of life compared with a control group that had only standard treatment. No improvement was observed in selfconcept, self-esteem, self-efficacy and stigma on Link Perceived Stigma Questionnaire (LPSQ) (Link et al. 1989) in repeated research in 2007 (McCay et al. 2007). Knight et al. (2006) developed a program that combined cognitive behavioral techniques and education about the illness. Topics were focused on stigma, self-esteem and better coping with the illness with the aim of empowerment. The program led to increases in self-esteem and decreases in depression, positive and negative symptoms, and general psychopathology, but did not improve empowerment as measured on The Boston University Empowerment Scale (BUES) (Rogers et al. 1997). Lucksted et al. (2011) developed a protocol-based Ending Self-Stigma (ESS) group program combining lecture, discussion, sharing of personal experiences, cognitive methods and group support. The results showed statistically significant reduction in self-stigma, increase in recovery and no statistically significant increase in empowerment. MacInnes and Lewis (2008) developed a structured group program using cognitive therapy with special emphasis on unconditional selfacceptance with educational input. Education topics included the stress-vulnerability model and coping strategies for dealing with stress. The results showed a decrease in stigma perception measured by LPSQ (Link et al. 1991), enhanced self-acceptance and nonsignificant increase in self-esteem. Funget et al. (2011) developed a program that includes five interventions: education about the illness, cognitive behavioral therapy, motivational interviewing, social skills training and achieving goals. They found increases in selfesteem as measured on the Chinese self-stigma scale (Fung et al. 2007). Our review of self stigma reduction programs discovered that only two studies (Shin \& Lukens 2002, Aho-Mustonen et al. 2011) have investigated the impact of education about the illness on selfstigma reduction, other programs combine education and cognitive methods in the group, focusing on the topic of stigma.

In our study we wanted to determine whether group psychoeducation (Štrkalj-Ivezić 2011) combining the education about the illness and stigma leads to reduction in the level of self-stigma, reduced perception of discrimination and increased empowerment (for more details on interventions and the differences in relation to other programs see the "Subject and method" section ).

\section{SUBJECTS AND METHODS}

\section{Interventions}

The Group Psychoeducation method (GP) (ŠtrkaljIvezić 2011) used in our study was designed as a brief supportive psychodinamic group psychotherapy focus on psychoeducation in group based on the principles of recovery and empowerment with the aim of relapse prevention, increased insight into illness, reduction of self-stigma and promotion of better strategies for coping with social stigma and discrimination. The program integrates elements of education about the illness, cognitive techniques for dealing with attitudes and beliefs, and psychodynamic approach for dealing with emotional reactions associated with the illness and stigma. The group setting stimulates discussion about various topics related to illness such as biopsychosocial model, stress-vulnerability theory, symptoms, treatment, relapse prevention plan, stigma stereotype awareness, cognitive-behavioral model of connection between thoughts, feelings and behaviors, stereotype rejection and coping with stigma and discrimination. Disclosure of personal experience of the illness, stigma and application of successful strategies in dealing with stigma and discrimination are encouraged. Information about the illness and stigma overlapped in the majority of sessions. All topics about the illness and stigma are processed in a way that suggests a possibility of recovery and facilitates empowerment. Therapeutic factors related to the group itself (Yalom 2005) such as group cohesion, universality, altruism, restoring hope, interpersonal learning and counseling help in the development of a positive experience of self and the identification with the empowered group and not with stigmatized persons. The program has 12 sessions.

The program has been run by the first author, who is a group analyst with experience in group psychotherapy for persons with psychoses (ک̌trkalj-Ivezić \& Urlic 2015). Included in the education are psychiatry residents who have completed their first level of education in group psychotherapy who will then go on to lead the psychoeducattion groups as a part of their training. Although most of the programs mentioned in the introduction are implemented in a group setting, none of them have group psychotherapy characteristics. Although our program has similarities with other programs in its use of educational themes related to the stress vulnerability theory and some elements of CBT, what makes the approach unique is psychoeducation conducted in the form of short group psychodynamic psychotherapy, using psychoeducation as its topic of focus. The group promotes open, free floating, discussion of matters that help increase the level of knowledge and experiences of psychosis and schizophrenia by stimulating the members to share their own experiences with illness, as well as their attitudes and reactions to the illness and the meaning and impact 
it has had on their lives with the aim of promoting insight into illness connected with the recovery. By using therapeutic factors of group psychotherapy such as group cohesion and interpersonal learning, patients are stimulated to share personal experiences with illness including personal views on causality and their reaction to illness, promoting positive attitudes towards recovery what stimulate stigma stereotype rejection.

\section{Participants and study design}

In this study Solomon four-group design was used. The study participants were 80 patients of Psychiatric Hospital Vrapče, Zagreb, Croatia, all with diagnose of schizoprenia referred by psychiatrists for the outpatient group psychoeducation. All patients were outpatients in a stabilized phase of their illness but some of them still had some residual positive and/ or negative simptoms. Despite the small sample size, using the Solomon fourgroup research design results in adequate statistical power, according to some authors, even greater than that of the posttest-only control group design on the same sample size (Braver Walton \& Braver 1988). Depending on when the referral was received the first 40 patients were allocated to experimental group $(\mathrm{N}=40)$ and the other 40 to control group $(\mathrm{N}=40)$, following the confirmation of the diagnosis of schizophrenia according to the $10^{\text {th }}$ revision of the International Statistical Classification of Diseases and Related Health Problems (ICD-
10) criteria by the psychiatristleading the group. The patients from the experimental group received 12 sessions of group psychoeducation over 3 months. The control group consisted of patients on the waiting list for psychoeducation. Both groups also received standard treatment, which consisted of antipsychotic medication and monthly reviews by psychiatrist. 40 subjects from the experimental group were treated in two separate groups by the same group leader. All participants were of Caucasian background and residents of Croatia. After complete description of the study to the participants, written informed consent was obtained. The study was approved by the Ethics Committee of the Psychiatric Hospital Vrapce, where the research was conducted. Half of participants that were randomly chosen $(\mathrm{N}=40,20$ participants from experimental and 20 from control group) filled out the rating scales before the beginning of the experimental group program. All of the participants filled out rating scales after the completion of 12 sessions, i.e. after 12 weeks. Demographic data are summarized in Table 1.

\section{Measurements}

The Internalized Stigma of Mental Illness Scale (ISMI) (Ritsher et al. 2003) assesses the mental health service users' experiences of self-stigma. Strong internal consistency $(\alpha=0.90)$ and test-retest reliability $(r=0.92)$ have been reported for the İSMI (Ritsher et al. 2003).

Table 1. Demographic data of the study participants

\begin{tabular}{|c|c|c|c|c|}
\hline & \multicolumn{2}{|c|}{ A - Control Group } & \multicolumn{2}{|c|}{ B - Experimental Group } \\
\hline & $\mathrm{N}$ & $\%$ & $\mathrm{~N}$ & $\%$ \\
\hline \multicolumn{5}{|l|}{ Sex } \\
\hline Male & 32 & 80.0 & 17 & 42.5 \\
\hline Female & 8 & 20.0 & 23 & 57.5 \\
\hline \multicolumn{5}{|l|}{ Age } \\
\hline to 30 years & 12 & 30.0 & 3 & 10.3 \\
\hline $31-40$ years & 7 & 17.5 & 9 & 31.0 \\
\hline $41-50$ years & 11 & 27.5 & 12 & 41.4 \\
\hline over 50 years & 10 & 25.0 & 5 & 17.2 \\
\hline \multicolumn{5}{|l|}{ Educational level } \\
\hline Elementary School & 5 & 12.8 & 4 & 10.3 \\
\hline Secondary school & 27 & 69.2 & 22 & 56.4 \\
\hline Tertiary education & 7 & 17.9 & 10 & 25.6 \\
\hline Postgraduate degree & 0 & & 3 & 7.7 \\
\hline \multicolumn{5}{|l|}{ Current Residence } \\
\hline Own house/ flat & 4 & 10.0 & 8 & 20.0 \\
\hline Relatives' home & 22 & 55.0 & 23 & 57.5 \\
\hline Rental house/flat & 4 & 10.0 & 2 & 5.0 \\
\hline $\begin{array}{l}\text { Other (Hospital/ Boarding house/ Retirement home/ } \\
\text { Foster family/ Homeless) }\end{array}$ & 10 & 25.0 & 7 & 17.5 \\
\hline \multicolumn{5}{|l|}{ Household members } \\
\hline Spouse / children & 18 & 45.0 & 28 & 70.0 \\
\hline Parents/ cousins & 7 & 17.5 & 6 & 15.0 \\
\hline Friends/ flat mate & 6 & 15.0 & 3 & 7.5 \\
\hline Alone & 7 & 17.5 & 1 & 2.5 \\
\hline TOTAL & 40 & 100 & 40 & 100 \\
\hline
\end{tabular}


Global Alliance for Mental Health Europe (GAMIAN Europe) stigma research (Brohan et al. 2010) also found the scalehad high internal consistency $(\alpha=0.94)$. This was also confirmed for Croatian translation of the scale ( $\alpha=0.92$ ) (Gruber 2011). In this study $\alpha=0.90$.

The Boston University Empowerment Scale (BUES) (Rogers et al. 1997) measures empowerment. The scale demonstrated adequate internal consistency $(\alpha=0.86)$. GAMIAN's stigma research (Brohan et al. 2010) found adequate internal consistency $(\alpha=0.87)$. For Croatian sample alpha was 0.82 (Gruber 2011). In this study $\alpha=0.79$.

The Perceived Devaluation and Discrimination Scale (PDD) (Link et al. 1989) measures the extent to which a person believes that most people will devalue or discriminate against someone with mental illness. GAMIAN's research on stigma found that the scale had moderate internal consistency $(\alpha=0.86)$ (Brohan et al. 2010), whilst in the Croatian sample alpha was 0.77 (Gruber 2011). In this study $\alpha=0.79$.

All three study measures (ISMI, PDD, BUES) are scored on a 4-point Likert scale with possible scores ranging from 1 to 4 .

\section{Statistical analysis}

Descriptive statistics were calculated before and after the group psychoeducation for experimental and control group on ISMI, PDD, BUES (Table 2). To determine the relationship between self-stigma, empowerment and perceived discrimination (the dependent variables) and exposure to psychoeducation (independent variable), while accounting for a potential influence of pretesting, a two-way analysis of variance and a simple analysis of variance with repeated measures were used. Means and standard deviations on ISMI, PDD, BUES were calculated before and after the group psychoeducation for experimental and control group (Table 2). A sample t-test was used to determine if there was a significant difference between control and experimental group that were exposed to a pretest. As a first way of testing the influence of pretest, a sample t-test was also used to determine potential difference between participants that were exposed to pretest and those who only filled scales after intervention. Statistical analysis was performed using Statistica for Windows.

Table 2. Means and standard deviation on the ISMI, PDD, BUES before and after the 12 weeks for control and psychoeducation groups

\begin{tabular}{|c|c|c|c|c|c|c|c|c|}
\hline Scale & Group & Timing & $\mathrm{N}$ & Mean & SE & SD & Min. & Max. \\
\hline \multirow{4}{*}{ ISMI } & \multirow{2}{*}{ A - Control Group } & Before & 20 & 2.46 & 0.09 & 0.39 & 1.55 & 3.34 \\
\hline & & After & 40 & 2.43 & 0.05 & 0.29 & 1.66 & 3.03 \\
\hline & \multirow{2}{*}{ B - Psychoeducation Group } & Before & 20 & 2.45 & 0.11 & 0.48 & 1.86 & 3.69 \\
\hline & & After & 40 & 2.20 & 0.07 & 0.41 & 1.41 & 3.59 \\
\hline \multirow{4}{*}{ BUES } & \multirow{2}{*}{ A - Control Group } & Before & 20 & 2.48 & 0.09 & 0.39 & 1.65 & 3.18 \\
\hline & & After & 40 & 2.56 & 0.06 & 0.36 & 1.88 & 3.53 \\
\hline & \multirow{2}{*}{ B - Psychoeducation Group } & Before & 20 & 2.53 & 0.08 & 0.35 & 1.94 & 3.24 \\
\hline & & After & 40 & 2.67 & 0.06 & 0.36 & 1.71 & 3.41 \\
\hline \multirow{4}{*}{ PDD } & \multirow{2}{*}{ A - Control Group } & Before & 20 & 2.61 & 0.08 & 0.34 & 2.17 & 3.67 \\
\hline & & After & 40 & 2.59 & 0.05 & 0.33 & 2.17 & 3.83 \\
\hline & \multirow{2}{*}{ B - Psychoeducation Group } & Before & 20 & 2.65 & 0.10 & 0.45 & 1.92 & 3.67 \\
\hline & & After & 40 & 2.57 & 0.07 & 0.45 & 1.75 & 3.92 \\
\hline
\end{tabular}

Table 3. F-ratios, t-ratios, significance level and effect sizes for all the analyses performed to test the effect of treatment on self-stigma, empowerment and perception of discrimination, by steps

\begin{tabular}{llrrc}
\hline \multirow{3}{*}{ ISMI } & Effect & $\mathrm{F} / \mathrm{t}^{*}$ & $\mathrm{p}$ & $\eta_{\mathrm{p}}{ }^{2}$ \\
& Treatment main effect & 8.18 & 0.005 & 0.097 \\
& Pretest main effect & 0.53 & 0.467 & 0.007 \\
& Treatment * Pretest interaction & 0.44 & 0.507 & 0.006 \\
& Treatment main effect & 1.74 & 0.192 & 0.022 \\
& Pretest main effect & 0.26 & 0.610 & 0.003 \\
\multirow{3}{*}{ BUES } & Treatment * Pretest interaction & 1.37 & 0.245 & 0.018 \\
& Repeated measures ANOVA - Time flow & 6.40 & 0.016 & 0.144 \\
& Repeated measures ANOVA - Treatement * time interaction & 2.14 & 0.152 & 0.053 \\
& t-test on un-pretested groups & -0.11 & 0.913 & \\
& Treatment main effect & 0.06 & 0.812 & 0.001 \\
& Pretest main effect & 3.30 & 0.073 & 0.042 \\
& Treatment * Pretest interaction & 0.19 & 0.668 & 0.002 \\
& Repeated measures ANOVA -Time flow & 3.06 & 0.088 & 0.075 \\
& Repeated measures ANOVA - Treatement*time interaction & 0.49 & 0.488 & 0.013 \\
\hline
\end{tabular}




\section{RESULTS}

Participants in the Group Psychoeducation (GP) achieved reduction in internalized stigma in comparison to the waiting list control. Sample t-test was used to determine if there was a significant difference between the control and experimental group exposed to the pretest. There was no statistically significant difference between the groups prior to the intervention with regards to self-stigma $(\mathrm{t}(38)=0.07, \mathrm{p}=0.945)$, empowerment $(\mathrm{t}(38)=-0.40 \mathrm{p}=0.691)$, and perception of discrimination $(\mathrm{t}(38)=-0.33, \mathrm{p}=0.743)$.

Testing the effects of the intervention was divided into several steps for each scale, following analysis suggestions suitable for Solomon's research design (Braver Walton \& Braver 1988).

As a first step, we examined the main effect of the pretest on all results. In order to exclude the intervention effect, analysis was carried out only on the post-intervention results of two control groups: the group that was exposed to pretest, and the group that was only tested after the intervention. No statistically significant differences were found in the level of self-stigma $(\mathrm{t}(38)=$ $0.06, \mathrm{p}=0.956)$, empowerment $(\mathrm{t}(38)=-0.46, \mathrm{p}=0.646)$ or perception of discrimination $(\mathrm{t}(38)=-1.16, \mathrm{p}=0.252)$.

As a second step, $2 \times 2$, factorial analysis of variance was used. The results showed no statistically significant main effect of pretesting $(\mathrm{F}(1,76)=0.53 ; \mathrm{p}=0.467)$ or interaction of pretesting and intervention $(\mathrm{F}(1,76)=0.06$; $\mathrm{p}>0.507)$. However, a statistically significant main effect of the intervention was found $(F(1,76)=8.18$; $\mathrm{p}=0.005)$. Subjects in the experimental group, involved in psychoeducation, had significantly lower score on self-stigma measurements as compared to the control group. Effect size, presented by partial eta squared shows that $9.7 \%$ of self-stigma variance can be explained by psychoeducation effect $\left(\eta_{\mathrm{p}}{ }^{2}=0.097\right.$; Table 3$)$. Comparisons of means for these groups are shown in Table 4. Regardless of pretesting, after education, experimental groups had lower scores $(M=2.15$ and $\mathrm{M}=2.26$ ) on self-stigma scale than the control group $(\mathrm{M}=2.43$ and $\mathrm{M}=2.44)$.

Since main effect of pretest and interaction of pretest with treatment were not statistically significant, and at the same time, main effect of treatment was, these findings are sufficient to conclude an existing significant effect of psychoeducation on lowering selfstigma, regardless of exposure to pretesting.

Same analyses were used to determine the effect of psychoeducation on the level of empowerment. Although, the increase in empowerment measures was higher in the psychoeducation group as shown in the Figure 1 and Table 2, 2x2 ANOVA shows its main effect did not reach statistical significance $(\mathrm{F}(1,76)=1.74 ; \mathrm{p}=0.192)$. Pretest main effect and pretest-treatment interaction also didn't show significance $(\mathrm{F}(1,76)=0.26 ; \mathrm{p}=0.610$ for main effect of pretest; and $F(1,76)=1.37 ; p=0.245$ ) for interaction effect).

Since no effect was proven by $2 \times 2$ ANOVA, we performed a third analysis, repeated measures ANOVA, with psychoeducation as factor. A statistically significant difference between the empowerment measures before and after was found for both - experimental and control group $\left(\mathrm{F}(1,38)=6.40 ; \mathrm{p}=.016 ; \eta_{\mathrm{p}}{ }^{2}=.144\right)$, while interaction between time and psychoeducation was not statistically significant $(F(1,38)=2.14 ; p=0.152)$. These results are indicating that both, standard treatment alone and group psychoeducation had a positive effect on the subjects' empowerment.

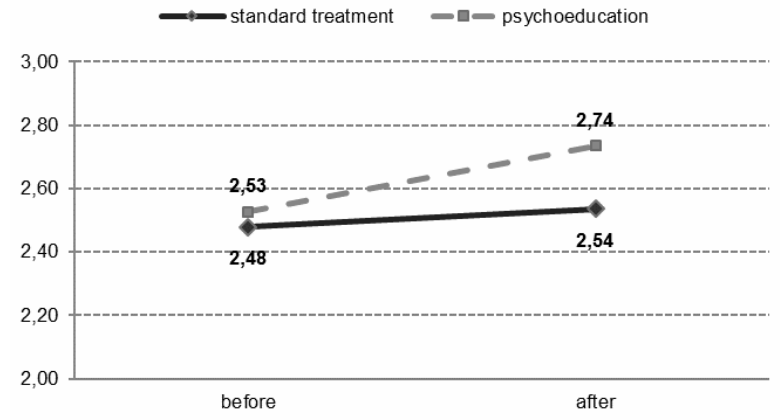

Figure 1. Results on the empowerment scale for participants who had standard treatment and those who underwent psychoeducation.

In the fourth step, we wanted to exclude the effect of psychoeducation on empowerment level. Independent sample t-test was carried out on two un-pretested groups. Like in previous analyses, no significant difference between experimental and control group was found $(\mathrm{t}(38)=-0.11 ; \mathrm{p}=0.913)$.

Table 4. Means and standard deviation on the ISMI, PDD, BUES with regards to experimental and control group and pre-test exposure

\begin{tabular}{|c|c|c|c|c|c|c|c|c|}
\hline \multirow{2}{*}{$\begin{array}{l}\text { Group } \\
\text { Scale }\end{array}$} & \multicolumn{2}{|c|}{$\begin{array}{c}\text { Control } \\
\text { with pretest }\end{array}$} & \multicolumn{2}{|c|}{$\begin{array}{c}\text { Control } \\
\text { without pretest }\end{array}$} & \multicolumn{2}{|c|}{$\begin{array}{c}\text { Experimental } \\
\text { with pretest }\end{array}$} & \multicolumn{2}{|c|}{$\begin{array}{l}\text { Experimental } \\
\text { without pretest }\end{array}$} \\
\hline & Mean & SD & Mean & $\mathrm{SD}$ & Mean & $\mathrm{SD}$ & Mean & $\mathrm{SD}$ \\
\hline ISMI (before) & 2.46 & 0.39 & & & 2.45 & 0.48 & & \\
\hline ISMI (after) & 2.43 & 0.27 & 2.44 & 0.32 & 2.15 & 0.35 & 2.26 & 0.47 \\
\hline BUES (before) & 2.48 & 0.39 & & & 2.53 & 0.35 & & \\
\hline BUES (after) & 2.54 & 0.39 & 2.59 & 0.33 & 2.74 & 0.37 & 2.60 & 0.34 \\
\hline PDD (before) & 2.61 & 0.34 & & & 2.65 & 0.45 & & \\
\hline PDD (after) & 2.53 & 0.25 & 2.65 & 0.39 & 2.48 & 0.32 & 2.67 & 0.54 \\
\hline
\end{tabular}


Taking into consideration all findings, we can conclude that there is no statistically significant effect of psychoeducation on the level of empowerment. However, an elapse in time in combination with standard schizophrenia treatment, showed significant effect on increasing patient's empowerment, regardless of psychoeducation.

We obtained similar results when testing effects of treatment on perception of discrimination. Psychoeducation did not show statistically significant main effect on the perception of discrimination $(\mathrm{F}(1,74)=0.06 ; \mathrm{p}=0.812)$ and neither did interaction of psychoeducation and pretest $(\mathrm{F}(1,74)=0.19 ; \mathrm{p}=0.668)$. Repeated measures ANOVA also did not show statistically significant main effect of treatment $(\mathrm{F}(1,38)=3.06 ; \mathrm{p}=0.088)$, or interaction of pretest and treatment $(\mathrm{F}(1,38)=0.49 ; \mathrm{p}=0.488)$. As a final step, independent sample t-test on two unpretested groups was also statistically insignificant $(\mathrm{t}(38)=-0.11 ; \mathrm{p}=0.912)$, indicating that there is no effect of psychoeducation on the level of perception of discrimination.

\section{DISCUSSION}

Stigma and self-stigma lead to difficulties in recovery from schizophrenia (Knight et al. 2006). Insight into illness is related to negative as well as positive influence on outcome of schizophrenia (Lysaker et al. 2007, Staring et al. 2009). Patients with high insight into illness and low level of self stigma seem to be best off across various outcome parameters (Lysaker et al. 2007). So we expect that interventions which increase insight into illness combined with reduced self stigma interventions should increase recovery from schizophrenia, which should be welcome in clinical practice. A meta-analysis of the efficacy of psychoeducation confirm that psychoeducation has many favorable effects but does not lead to increased insight about one's own illness (Xia et al. 2011). Paradoxical results of the influence of insight can be interpreted as meaning that a person attributes to his or her own diagnosis (Lysaker et al. 2007). Many patients feel that the diagnosis of schizophrenia inevitably implicates poor prognosis and outcomes (Roe \& Kravetz 2003). So we assumed that psychoeducational program with recovery orientation combining education about the illness and stigma uses therapeutic factors of the group setting (Štrkalj-Ivezić 2011) would contribute to a reduction of self stigma. We also wanted to examine whether such a program would also lead to reduction in perceptions of discrimination and increases in empowerment. When a person is diagnosed with schizophrenia they face a collective stereotype of mental illness that involves misconceptions of weak personality, incompetence, danger and incurability, which affect the value image of the self. In this context insight into illness is related to insight into stereotype with low expectation of recovery (Štrkalj-Ivezić 2013). In order to prevent negative consequences of this process, a person with schizophrenia should be offered early in their treatment the recovery perspective of their illness as opposed to the "chronic" perspective based on stereotype. Without this help there is a danger of accepting the stereotype, which leads to self- stigma or rejection of the diagnosis and treatment as the person does not want to identify with the group of stigmatized persons. Group setting is suitable for working with self concept through the use of a series of group therapeutic factors helping to build insight, increase self-esteem, reduce self-stigma and facilitate the process of identification with the group of recovered persons as opposed to the group of stigmatized persons. This facilitates the process of stereotype rejection important for self-stigma prevention. Group psychoeducation program used in this study achieved statistically significant reduction the level of self stigma amongst the participants. Increase in empowerment did not achieve the level of statistical significance. Group psychoeducation also did not influence perception of discrimination. Based on our observation of the group process and comparing it with similar programs we believe that there are two important elements that lead to the reduction of self-stigma. One is the use of information about the illness in the framework of recovery that discourages the term schizophrenia being linked with beliefs based on stereotype of "chronic" and poor outcome. The other is identification with the group of persons who were able to recover, which is the opposite of identification with the stigmatized group diagnosed as "schizophrenics". Group discussion guided by the principles of recovery and empowerment encourages identification with a group of empowered people who can gain control over their illness and their lives. This is contrary to the perception of helplessness, chronicity and incurability, which is consciously or unconsciously often transmitted in the standard treatment that is not based on the principles of recovery and empowerment. We believe that breaking the connection between the diagnosis of schizophrenia and its stereotype and facilitating the identification with empowered persons is crucial factor in self stigma reduction program and for prevention of negative influence of stigma on recovery from schizophrenia.

Our result on empowerment is in line with other studies. We agree with the opinion of Knight et al. (2006), who suggest the treatment can be expected to prepare the patients for starting the process of empowerment, while the real empowerment is outside of the therapeutic situation and very often requires the presence of other elements such as the opportunities in the society that allow people to demonstrate competence. Psychoeducation did not have statistically significant effect on perception of discrimination, opposite to findings from Shin and Lukens (Shin \& Lukens 2002) study. Some researchers (Link et al. 2001, Watson \& River 2005) argue that there is no direct correlation between self-stigma and perception of discrimination 
and that perception of discrimination is not in itself a measure of self-stigma but a measure of awareness that stigma and discrimination exist. The matter is not so simple, as shown by others, who found a connection between the perception of discrimination and selfstigma (Brohan et al. 2010). The fact that perception of discrimination is not solely the measure of perceived discrimination is in line with our observations in the group, where a patient reported social isolation related to defending themselves from the hurt of expected discrimination of others.

The results of our research are the most similar to the results of the study by Luckstedet al. (2011), who also found a decrease in self-stigma without significant improvement in empowerment. They used the same scales to measure self-stigma and empowerment.

All interventions that have been provided in the group setting, regardless of whether they used education about the illness alone (Shin \& Lukens 2002, AhoMustonen et al. 2011) or combined the information about the illness and stigma with cognitive and other approaches (Knight et al. 2006, McCay et al. 2006, MacInnes\& Lewis 2008, Lucksted et al. 2011) were shown to be successful. This may suggest that the group setting facilitates the process of the reduction of selfstigma through therapeutic factors associated with the group setting itself. This should be considered in planning of programs for reduction of self-stigma.

The current research was a naturalistic study rather than a randomized controlled study. Wait list control was one of the limitations of this study, and positive expectation of future participation in the program might have interfered with the results, reducing the difference between the groups. Another limitation is a small number of participants. We did not measure other factors that may affect the results e.g. patient - therapist relationship, social network, psychopatology, self esteem, insight into illness etc.

\section{CONCLUSION}

Psychoeducation about the illness and stigma brought in the context of recovery helps to break the association between the diagnosis and the threatening image of stereotype, and helps the rejection of cultural stereotypes of mental illness as personally irrelevant, so it should be a key part of successful self-stigma reduction program. Discussion of the meaning attached to the diagnosis to assist the patient so that the stereotype of mental illness does not affect them at the personal level should be offered to every patient regardless of the treatment duration.

\section{Acknowledgements: None.}

\section{Conflict of interest: None to declare.}

\section{Contribution of individual authors:}

All authors participate in design of the study, literature searceh ana analyses, interpretation of date and writeing of the manuscript. Second author also participate in selecion of participans, and first author provided intervention in the group.

\section{References}

1. Aho-Mustonen K, Tiihonen J, Repo-Tiihonen E, Ryynänen $O-P$, Miettinen R, Räty H: Group psychoeducation for long-term offender patients with schizophrenia: an exploratory randomised controlled trial. Crim Behav Ment Heal 2011; 21:163-76.

2. Braver Walton MC, Braver SL: Statistical treatment of the Solomon Four-Group Design: A meta-analytic approach. Psychological Bulletin 1988; 104:150-154.

3. Brohan E, Elgie R, Sartorius N, Thornicroft G, GAMIANEurope Study Group: Self-stigma, empowerment and perceived discrimination among people with schizophrenia in 14 European countries: the GAMIAN-Europe study. Schizophr Res 2010; 122:232-8.

4. Corrigan P, Watson A, Barr L: The Self-Stigma of Mental Illness: Implications for Self-Esteem and Self-Efficacy. $J$ Soc Clin Psychol 2006; 25:875-884.

5. Fung KMT, Tsang HWH, Cheung W: Randomized controlled trial of the self-stigma reduction program among individuals with schizophrenia. Psychiatry Res 2011; 189:208-14.

6. Fung KMT, Tsang HWH, Corrigan PW, Lam CS, Cheung $W$ : Measuring self-stigma of mental illness in China and its implications for recovery. Int J Soc Psychiatry 2007; 53: 408-18.

7. Gruber E. Kroskulturalna analiza posljedica društvene stigmatizacije osoba s psihičkim poremećajima. Doktorska disertacija.Filozofski fakultet Sveučilišta u Zagrebu; Zagreb, 2011.

8. Hayward P, Wong G, Bright JA, Lam D: Stigma and selfesteem in manic depression: an exploratory study. J Affect Disord 2002; 69:61-7.

9. Knight MTD, Wykes T, Hayward P: Group Treatment of Perceived Stigma and Self-Esteem in Schizophrenia: A Waiting List Trial of Efficacy. Behav Cogn Psychother 2006; 34:305-18.

10. Link B, Cullen F, Struening E, Shrout P, Dohrenwend B: A modified labeling theory approach in the area of mental disorders: An empirical assessment. Am Sociol Rev 1989; 54:400-23.

11. Link BG, Mirotznik J, Cullen FT: The effectiveness of stigma coping orientations: can negative consequences of mental illness labeling be avoided? J Health Soc Behav 1991; 32:302-20.

12. Link BG, Struening EL, Neese-Todd S, Asmussen S, Phelan JC: Stigma as a barrier to recovery: The consequences of stigma for the self-esteem of people with mental illnesses. Psychiatr Serv 2001; 52:1621-6.

13. Lucksted A, Drapalski A, Calmes C, Forbes C, DeForge $B$, Boyd J: Ending self-stigma: pilot evaluation of a new intervention to reduce internalized stigma among people with mental illnesses. Psychiatr Rehabil J 2011; 35:51-4. 
14. Lysaker PH, Roe D, Yanos PT.Toward understanding the insight paradox: internalized stigma moderates the association between insight and social functioning, hope, and self-esteem among people with schizophrenia spectrum disorders. Schizophr Bull 2007; 33:192-9.

15. MacInnes DL \& Lewis M: The evaluation of a short group programme to reduce self-stigma in people with serious and enduring mental health problems. J Psychiatr Ment Health Nurs 2008; 15:59-65.

16. McCay E, Beanlands H, Leszcz M, Goering P, Seeman M $V$, Ryan $K$, et al.: A group intervention to promote healthy self-concepts and guide recovery in first episode schizophrenia: A pilot study. Psychiatr Rehabil J 2006; 30:105-11.

17. McCay E, Beanlands H, Zipursky R, Roy, $P$ et al.: A Randomised Controlled Trial of a Group Intervention to Reduce Engulfment and Self-stigmatisation in First Episode Schizophrenia. Aust e-Journal Adv Ment Heal 2007; 6:1-9.

18. Mittal D, Sullivan G, Chekuri L, Allee E, Corrigan PW: Empirical Studies of Self-Stigma Reduction Strategies: A Critical Review of the Literature. Psychiatr Serv 2012; 63:974-81.

19. Ritsher JB, Otilingam PG, Grajales M: Internalized stigma of mental illness: psychometric properties of a new measure. Psychiatry Res 2003; 121:31-49.

20. Rappaport J: Terms of empowerment/exemplars of prevention: toward a theory for community psychology. Am J Community Psychol 1987; 15:121-148.

21. Roe D \& Kravetz S: Different ways of being aware of a psychiatric disability: a multifunctional narrative approach to insight into mental disorder. J Nerv Ment Dis 2003; 191:417-24.

22. Rogers ES, Chamberlin J, Ellison ML, Crean T: A consumer-constructed scale to measure empowerment among users of mental health services. Psychiatr Serv 1997; 48:1042-7.

23. Sartorius $N \&$ Schulze H: Global Programme of the World Psychiatric Association. Reducing the Stigma of Mental Illness: A Report from a Global Programme of the World Psychiatric Association. Cambridge University Press, Cambridge, UK; New York, 2005.

24. Shin SK \& Lukens EP: Effects of psychoeducation for Korean Americans with chronic mental illness. Psychiatr Serv 2002; 53:1125-31.

25. Staring $A B P$, Van der Gaag $M$, Van den Berge $M$, Duivenvoorden HJ, Mulder CL: Stigma moderates the associations of insight with depressed mood, low selfesteem, and low quality of life in patients with schizophrenia spectrum disorders. Schizophr Res 2009; 115:363-9.

26. Śtrkalj-Ivezić S: Psihoza, shizofrenija, shizoafektivni poremećaj, bipolarni poremećaj. Psihoedukacija između informacije i psihoterapije. Medicinska naklada, Zagreb, 2011.

27. Strkalj-Ivezić S: Stigma in clinical practice. Psychiatr Danub 2013; 25(Suppl 2):S200-2.

28. Strkalj Ivezić S, Urlić I: The capacity to use group as a corrective symbiotic object in group analytic psychotherapy of patients with psychosis Group Analysis 2015; 48:315-332.

29. Watson $A$ \& River L: From self stigma to empowerment. In: Corrigan P, editor: A Comprehensive Review of the Stigma of Mental Illness: Implications for Research and Social Change, 145-164. American Psychological Association, Washington, 2005.

30. Xia J, Merinder LB, Belgamwar MR: Psychoeducation for schizophrenia. Schizophr Bull 2011; 37:21-2.

31. Yalom I: The theory and practice of group psychotherapy. 5th ed. Basic Books, New York, 2005.

Correspondence:

Professor Slađana Štrkali Ivezić, MD, PhD

Psychiatric Clinic Vrapče

Bolnička cesta 32, 10000 Zagreb, Croatia

E-mail: sladjana.strkalj-ivezic@zg.t-com.hr 